\title{
Comparative analysis of demographic potential of rural territories of the central black earth
}

\author{
Evgeny Reutov, Marina Reutova, Svetlana Vangorodskaya, and Galina Gaidukova* \\ Belgorod State University, 308015 Belgorod, Russia
}

\begin{abstract}
The article presents the substantiation of the methodology for comparative analysis of the demographic potential of rural areas and identifies the main trends in the development of the demographic potential of rural areas of the Central Black Earth Economic Region. Rural areas are considered as an essential factor in the reproduction of the natural, economic, demographic and socio-cultural potential of Russian society. It has been substantiated that the main problems hindering sustainable social development are mainly due to the change in the balance between the urban and rural populations characteristic of the era of accelerated industrialization. The definition of demographic potential as a set of opportunities and conditions for the development of territories lying in the sphere of population reproduction is given, and a great variability of the concept of demographic potential in sociological and demographic discourses is noted. Taking into account two key factors of population dynamics - fertility and migration, it is proposed to measure the demographic potential of Russian municipalities by using indicators such as the proportion of the population of reproductive age, the birth rate and the coefficient of migration inflow/outflow of the population. The expediency of using available statistical data, adapted in relation to the proposed research methodology, is shown. Based on the generalization and analysis of statistical data characterizing the natural and migration movement of the population of rural areas of five regions of the Central Black Earth Economic Region, as well as the results of the sociological study "Mental inequalities as a factor in the social polarization of the Russian province" conducted in the Belgorod and Voronezh regions in 2018-2019, it was concluded that the rural areas of the Central Black Earth Economic Region are characterized by heterogeneity of the demographic potential, which in the Kursk and Tambov regions is acquiring the character of obvious degradation, and the migration attractiveness of the territories (with the exception of suburbs) has rather negative values.
\end{abstract}

\section{Introduction}

With a sufficiently high degree of urbanization in the country, rural areas continue to be an essential factor in the reproduction of the natural, economic, demographic and sociocultural potential of Russian society. The share of the rural population of Russia (as of January 1,

\footnotetext{
* Corresponding author: g_gaidukova@bsu.edu.ru
} 
2021 ) is $25.34 \%$, and in some regions it is much higher. So, in the Altai Republic the share of the rural population is $70.72 \%$, in the Chechen Republic $-63.12 \%$, in the KarachayCherkess Republic $-57.12 \%$, in the Republic of Dagestan $-54.69 \%$. In the regions of the Central Black Earth Economic Region, the share of the rural population is lower than in the regions noted above, but still noticeably higher than the national average: in the Belgorod region $-32.51 \%$, in the Voronezh region $-32.04 \%$, in the Kursk region $-31.48 \%$, in Lipetsk $-35.37 \%$, in Tambov $-38.61 \%$ [1].

However, due to the process of urbanization, changes in the technological structure in the agricultural sector, degradation of social infrastructure, rural areas are currently losing their population. The only exceptions are mainly suburbs - rural settlements located along the perimeter of large cities and, in fact, are part of urban agglomerations. The change in the existing balance between the urban and rural populations, which is absolutely natural in the era of accelerated industrialization, at the present time, rather gives rise to a set of problems, rather than contributes to the sustainable development of society. The influx of the rural population into the cities leads to an excess supply of labor in the urban labor market and spins up the rise in property prices.

In turn, the decline in the rural population creates problems of a different kind. In the aggregate of resources for the development of rural areas, human and labor resources play a special role. A skilled workforce, along with production capacity and investment, is the backbone of economic growth. High or moderately high population density in rural areas prevents them from desertification and is a powerful driver of public, corporate and private investment in social infrastructure. There are many examples in social history when the disappearance or a sharp decrease in the population of certain territories led to the degradation of natural landscapes and technological infrastructure, not to mention their actual loss for the economies of countries and regions.

\section{Materials and methods}

The purpose of this article is to substantiate the methodology for comparative analysis of the demographic potential of rural areas and identify trends in the development of the demographic potential of rural areas of the Central Black Earth Economic Region, which includes Belgorod, Voronezh, Kursk, Lipetsk and Tambov regions.

The empirical basis of the article is statistical data characterizing the natural and migration movement of the population in rural areas of five regions of the Central Black Earth Economic Region, as well as the results of the sociological study "Mental inequalities as a factor in the social polarization of the Russian province" conducted in the Belgorod and Voronezh regions (in 2018 there was questionnaire survey, $\mathrm{N}=1200$ respondents, 600 in each region, in 2019 there was a series of semi-formalized interviews $(\mathrm{N}=50)$.

In the context of the study of the main factors of simple and extended reproduction of the population of rural areas, the concept of demographic potential plays a special role. Demographic potential must be distinguished from the actual demographic resources. The demographic resources of a territory are, first of all, people living on it, assessed by a set of quantitative and qualitative parameters in order to understand their contribution to the economic, social, cultural and other development of the territory. Unlike resources, demographic potential (from Latin potentia - strength, opportunity) is, rather, a set of opportunities and conditions for the development of territories lying in the sphere of population reproduction. So, for example, when analyzing the demographic resources of a particular territory, it will be necessary to take into account the number and proportion of the population of young people, skilled workers, etc. And when analyzing the demographic potential, along with the fixation and quantitative description of these groups, it will be 
extremely important to understand their values and attitudes concerning migration outside rural areas or the region as a whole.

At the same time, it should be noted that the concept of demographic potential is still quite varied in sociological and demographic discourses.

For the first time the concept of "demographic potential", according to some sources, was proposed to be introduced by the English demographer R. Fisher in the 1920s. R. Fisher metaphorically considered the birth of a person as receiving life "on credit", and the subsequent birth of his own children as "paying off the debt." Thus, the influence of the demographic potential on the development of society, according to R. Fischer, was traced only in the narrowly demographic sphere and was reflected in the birth rate. Moreover, the concept already introduced by R. Fisher has not received precise indicators in the demographic and statistical sciences of his day. According to other data, the concept of "demographic potential" was introduced by J. Stewart, who studied the factors of migration. He borrowed the concept of "potential" from physics and, using the concept of "gravitational potential, he believed that the interaction between masses of people is determined by connections similar to physical ones" [2].

The study of the demographic situation and the potential of rural areas has become widespread in European countries. Jadwiga Biganska, based on indicators characterizing population density, population structure by sex and age, population migration and vital statistics, assessed the potential of rural areas in Poland in 1999-2011 from a demographic point of view. The k-means method was used to classify and compare rural areas [3]. Trends in the development of economic and demographic processes in the region were outlined. L. Nimets, N. Guseva, K. Segida presented the characteristics of the spatial distribution of the population of the Kharkiv region, as well as the methodology for calculating the demographic potential, taking into account the qualitative and quantitative characteristics of the population and trends in its movement. Based on the results of the study, the authors calculated the demographic potentials of the regions of Ukraine and determined the place of the Kharkiv region among them, including its territorial differentiation in relation to the environment, which includes key components and cause-and-effect relationships of the socio-economic development of cities and districts [4]. Daniele Rama et al., using the example of rural Italy, analyzed the usefulness of the Facebook advertising platform, which offers a digital census of more than two billion of its users, to measure potential inequalities between rural and urban areas [5].

Later, in the study of migration processes in domestic science, the concept of "migration potential" prevailed, under which L.L. Rybakovsky and N.I. Kozhevnikov, for example, understood the "assessment of migration resources located in countries - possible donors for the recipient country" [6].

There have also been repeated attempts to develop a set of indicators for quantitative analysis of demographic potential.

So, outside the migration aspect of demography, it was proposed to evaluate the demographic potential also in person-years according to their number and life expectancy. This proposal is borrowed from the concept of "labor potential", where labor means the person existence in itself [7]. In the generalizing article by O.L. Rybakovsky and O.A. Tayunova notes that "demographic potential can mean both the potential for population growth and the potential for population growth for each, for several or for all components of the demographic movement of the population. Population growth potential shows general changes, possible general results of changes in population parameters. The population growth potential can be considered as the difference between the maximum (conditionally) admissible possibilities and the inertial scenario of demographic development" [2].

With regard to the topic of our research, the concept of the demographic potential of a territory has significant methodological value, which, from the point of view of O.L. 
Rybakovsky and O.A. Tayunova is formed, on the one hand, under the influence of fertility and mortality processes, and on the other, under the migration: "the demographic potential of a territory is, firstly, the reproductive capabilities of the resident population of a given territory, including retention or changes in the levels and trends of fertility and mortality, and, second, the possibilities of the population of migration-related regions of the region to change the size and structure of its population by migration" [2]. Also, these authors note the difference in measuring the demographic potential of the territory, depending on the methodology and purpose of its assessment: "depending on the time of assessment, the demographic potential can be either the level of demographic development achieved at the moment, or those opportunities that can be realized in the future" [2].

From the point of view of A.I. Kuzmina, "demographic potential as a synthetic category is not just the size or mass of the population of a country or a macroregion, but a certain system for assessing the potentials of its viability, marriage, fertility, divorce rate, the formation of sex, age and family and marriage structure and territorial mobility of the population (including pendulum migration)" [8].

M.L. Yashin and N.R. Aleksandrova propose to measure the demographic potential of Russian municipalities, using indicators such as population growth/decline rate, population size, share of the working-age population, fertility rate, fertility growth/decline rate, mortality rate, dynamics of mortality rate, natural decline rate of population, the coefficient of migration inflow/outflow of the population [9].

From our point of view, for the calculation and comparative analysis of the demographic potential of territories, it is advisable to use such indicators as the share of the population of reproductive age, the birth rate and the coefficient of migration inflow/outflow of the population. Thus, two key factors of population dynamics are indirectly taken into account fertility and migration. A certain problem is the lack of a unified methodological and publication model of territorial statistical measurements and the incompleteness of statistical data in relation to the rural areas of the regions of Russia. Proceeding from this, in the future, in the empirical analysis of the demographic potential of rural areas in the regions of the Central Black Earth Economic Region, available statistical data will be used, adapted in relation to the proposed research methodology.

The reproductive age in women, in accordance with the well-established methodology of demographic research, is considered to be the interval of 15-49 years [10]. However, within this interval, the birth rate is extremely heterogeneous and depends on the specific socioeconomic and socio-cultural conditions in certain societies. In Russia, the birth rate is sharply decreasing in relation to the group of women over 44 years old (in 2019 it was 3.0 children per 1000 women versus 82.9 in the group of women of reproductive age of 15-49 years old) [11]. Thus, in the calculation and comparative analysis, it is quite permissible to limit ourselves to the age of 15-44 years. For men, it is advisable to use the age interval of 20-49 years. Considered in the context of the demographic potential, the indicator of the proportion of the population of reproductive age allows, with certain reservations (indicators of actual childhood, socio-economic situation, measures of state support for motherhood and childhood, socio-cultural characteristics of the territorial community, etc.) to carried out the fertility forecast.

\section{Results and discussion}

In the Belgorod region, the aggregate share of men aged 20-49 and women aged 15-44 in the rural population, as of January 1, 2020, is $36.2 \%$, while as of January 1, 2016 it was $32.2 \%$ [12]. In the Kursk region, as of January 1, 2020, the share of the population of reproductive age is $32.7 \%$. As of January 1,2018 , it was $33.2 \%$ [13, 14] (an earlier value cannot be calculated due to lack of data). In other regions of the Central Black Earth Region, it was not 
possible to calculate the values of this indicator due to the lack of initial data. Thus, in two of the five regions of the Central Black Earth Region, opposite trends are observed: in the Belgorod Region, the share of the population of rural areas of reproductive age in 2015-2019 is has grown quite noticeably, which is due to the strong regional policy of stimulating individual housing construction; in the Kursk region for 2017-2019 this share, albeit insignificantly, decreased. Thus, in the Belgorod region, rural areas received a rather tangible impetus for the growth of birth rates in rural areas in the short and medium term. However, at the same time, the total fertility rate in rural areas of the Belgorod region has been consistently decreasing since 2015. If in 2015 it was 1.757, then in 2019 it was 1.404 [15]. To a large extent, the decrease in childbirth per woman of reproductive age neutralized the effect of an increase in the proportion of the population in rural areas of reproductive age. Nevertheless, the rate of natural growth of the rural population in the Belgorod region in 2019 was -8.3 , which, although it characterizes negatively the dynamics of natural reproduction, is still the highest value since 2010 [15].

Data on the migration movement of the population of the rural areas of the Belgorod Region are not available, it can only be assumed that the migration increase in the population of the region recorded in the last two decades has at least partially affected the rural areas.

In the Voronezh region, the rural population, as well as its share in the region's population from 2009 to 2019. consistently decreased [16]. However, apart from these data, the official statistical publications of the region do not contain other parameters of the natural demographic movement of the population in rural areas.

The migration growth of the population in rural areas of the Voronezh region amounted to 37.2 per 1000 people in 2019, which is the highest rate since 2015. Moreover, from 2015 to 2018 a decrease in migration growth was recorded down to its negative value (-8.3 in 2018) [16]. The lack of actual data allows us to build only hypothetical models, according to which the demographic potential of the rural territories of the Voronezh region is decreasing under the influence of the natural decline of the rural population, but it is partly compensated by an unstable migration increase.

In the Kursk region, in rural areas, the birth rate in 2019 was 7.0. At the same time, it has been consistently decreasing since 2014 (in which it was 11.1) with a simultaneous increase in the rate of natural population decline (from 10.9 to 12.5) [14]. Thus, in the Kursk region, the cumulative negative effect of all components of the demographic potential of rural areas was clearly demonstrated: a decrease in the proportion of the population of reproductive age - a decrease in the birth rate - a natural population decline.

The migration loss in rural areas of the Kursk region in 2019 was 199 people, but in 2018 it was even higher - 1986 people [14]. Nevertheless, migration processes exacerbate the negative dynamics of the demographic potential of the rural areas of the region.

In the Lipetsk region, the birth rate in rural areas in 2019 was 7.7 children per 1000 population. At the same time, since 2015, it has been consistently decreasing. Accordingly, the rate of natural population decline increased from 7.8 to 8.7 [17].

The migration growth of the rural population in the Lipetsk region in 2019 amounted to 689 people, while in 2018 a decline of 811 people was recorded [17].

Thus, we can state a decrease in the demographic potential of the rural areas of the Lipetsk region, albeit at a slower pace than in the Kursk region. The influence of migration processes on the demographic potential of the rural areas of the Lipetsk region is generally ambivalent; nevertheless, in the last year, the migration inflow of the population at least partially compensates for the decline in the demographic potential as a whole.

In the Tambov region, in rural areas, the rate of natural increase/decrease of the population in 2019 was -9.4 , in $2014--8.5$ [18]. Thus, in the mid-term retrospective, the demographic potential of the rural areas of the region has significantly decreased. 
At the same time, the migration loss of the rural population of the Tambov region in 2019 amounted to 2558 people [18, 19], significantly increasing the degradation of the demographic potential.

A sociological study we conducted earlier in two regions of the Central Black Earth Region - Belgorod and Voronezh regions - revealed a potential negative effect on the demographic potential of the regions of the existing migration attitudes of the population. Thus, a sociological survey conducted in 2018 ( $\mathrm{N}=1200$ respondents, 600 in each region) showed that $64.9 \%$ of respondents, in one way or another, have a potential readiness to migrate from the region of residence (the share of respondents who admitted for other reasons, leaving their region permanently or for a long period) and only $24.8 \%$ do not consider this option under any circumstances. At the same time, among young people 18-29 years old, the potential for migration readiness is $90.7 \%$, and among respondents $30-39$ years old $-71.89 \%$ (Fig. 1) [20].

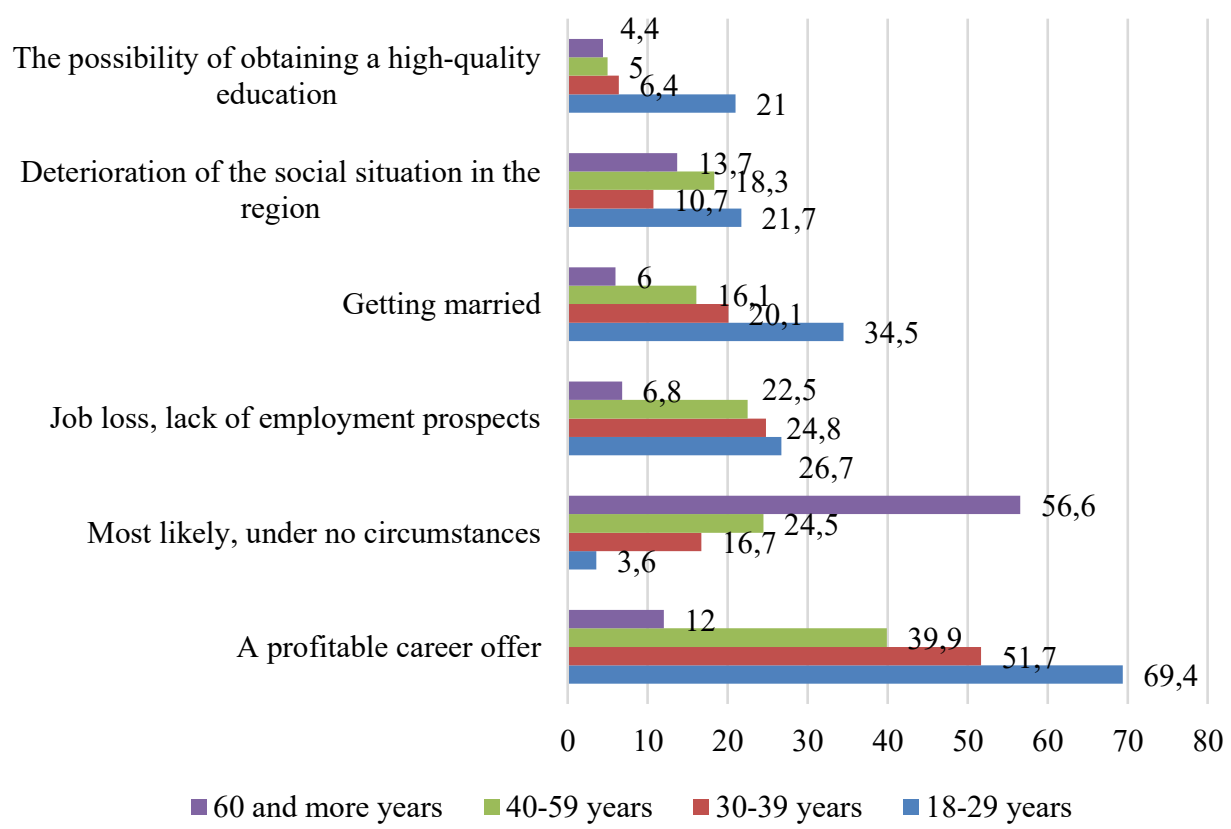

Fig. 1. The responses' overview on the question "Under what circumstances are you ready to move from your region permanently, or for a long time (from 4-5 years)?", \%

And although the attitudes towards territorial mobility are somewhat more pronounced among residents of large cities, in the assessments of rural residents identified in 2019 during focus groups, the topic of the absence or insufficiency of self-realization mechanisms emerges more clearly: "Of course, the city has more chances to achieve success in life. More opportunities to find yourself and in general... Find a more prestigious job and study, of course. Actually, we have nowhere to get education" (woman, 42 years old, village, Voronezh region); "You can't do it here... I think, in the city" (woman, 69 years old, Voronezh region); "Of course, in the city. You can already come to the village when you are already a professional in some area, for example, in the agricultural one. Then you can come and organize your business or connect to what is already there. But there is nothing to get here yet" (woman, 72 years old, village, Voronezh region); "If my child stays in the village, he will not be able to achieve what I would like, what he would have achieved" (woman, 30 years old, village, Belgorod region); "Well, how can you achieve much in a village with six 
yards? You need to study, get an education, go to a big city" (man, 50 years old, village, Belgorod region).

\section{Conclusion}

Thus, the rural areas of the Central Black Earth Economic Region are characterized by a heterogeneous demographic potential. Nevertheless, in most of them (Kursk, Lipetsk and Tambov regions), the processes of a decrease in the demographic potential are recorded, acquiring the character of an obvious degradation in relation to the Kursk and Tambov regions. A certain exception is the Belgorod region, where the proportion of the population of rural areas of reproductive age is growing, but the number of children is decreasing and, although its rates are somewhat slowing down, the natural decline of the rural population remains. At the same time, in the rural territories of the Kursk and Tambov regions, the migration outflow aggravates the process of natural population decline, and in the Voronezh, Lipetsk and, possibly, Belgorod regions, the migration increase only slightly compensates for it. At the same time, the migration attractiveness of rural areas (with the exception of suburbs), according to opinion polls, has rather negative values.

\section{Acknowledgments}

The article was carried out within the framework of the state task of the national research Belgorod State University for 2020, project No. 0624-2020-0027 «Socio-demographic determinants of rural development in the Central Chernozem economic region».

\section{References}

1. Rosstato Number and migration of the population of the Russian Federation in 20196 https://gks.ru/

2. O. L. Rybakovsky, O. A. Tayunova, Population, 2, 19-20 (2019)

3. Ja. Biegańska, Bulletin of Geography. Socio-economic Series, 20, 7-22 (2013)

4. L. Niemets, N. Guseva, K. Segida, Economic Annals-XXI, 3-4(1), 93-96 (2015)

5. D. Rama, Ye. Mejova, M. Tizzoni, K. Kalimeri, I. Webwr, WWW '20: Proceedings of The Web Conference 2020, April, 327-338 (2020)

6. L. L. Rybakovsky, N. I. Kozhevnikova, Assessment of the possible and necessary scale of attracting immigrants to Russia (2010)

7. V. M. Medkov, Demography (2004)

8. A. I. Kuzmin, Problems of modeling social processes: Russia and the countries of the Asia-Pacific region: materials of the Second All-Russian scientific-practical conference with international participation, Vladivostok, December 7-8, 183-187 (Vladivostok, 2016)

9. M. L. Yashina, N. R. Aleksandrova, International Research Journal, 5-3, 86-91 (2021)

10. D. A. Tuzov, Economics, Statistics and Informatics, 1, 121-126 (2010)

11. Russian statistical yearbook, https://rosstat.gov.ru/ (2020)

12. Statistical Yearbook. Belgorod region (Belgorod, 2016)

13. Statistical Yearbook. Kursk Region (Kursk, 2018)

14. Statistical Yearbook. Kursk Region (Kursk, 2020)

15. Statistical Yearbook. Belgorod region (Belgorod, 2020) 
16. Statistical Yearbook. Voronezh region (Voronezh, 2020)

17. Statistical yearbook. Lipetsk region (Lipetsk, 2020)

18. Statistical Yearbook. Tambov region (Tambov, 2020)

19. Statistical Yearbook. Tambov region (Tambov, 2015)

20. E. V. Reutov, M. N. Reutova, I. V. Shavyrina, Sociological Research, 6(46), 61-71 (2020) 